\title{
Zur ältesten christlichen Chronographie des Islam.
}

In der ZDMG 51 (1897) 569-588 veröffentlichte E. W. Brooks nach Handschriften des Britischen Museums den wichtigsten Teil einer anonymen syrischen Chronik. Das letzte darin mitgeteilte Ereignis fällt in das Jahr 843, doch ist der Hauptteil kurz nach 784 entstanden, so daB wir alle späteren Notizen als Zusatz eines Abschreibers betrachten können. Entstanden ist die Chronik zu Carrhae, denn 1) werden die Bischöfe dieser Stadt sehr oft erwähnt, 2) ist die Regierung Jazids III und Ibrahims übergangen, die nach Pseudodionysius in Mesopotamien nicht anerkannt wurden. Ihr Verfasser scheint ein Kleriker (oder Mönch) in Carrhae zu sein. Das letzte der mitgeteilten Stücke der Chronik weist eine dreifache Gliederung auf. Davon enthält der erste Teil byzantinisch-arabisch-kirchliche Notizen von 679 bis 728 . Dieser Teil bietet ein besonderes Interesse wegen seiner Beziehungen zu einer anderen Schrift, die nur wenige Jahrzehnte früher entstanden ist, nämlich zur sogenannten Continuatio Isidori byzantia-arabica.

Die Continuatio, herausgegeben von Mommsen in den Monumenta Germaniae Bd. XI, ist auBerhalb Spaniens zur Zeit der letzten Umajjiden entstanden, und zwar nach Schwenkow ${ }^{1}$ ) in Nordafrika (vielleicht in Alexandrien), oder wie Nöldeke, wie es scheint, mit mehr Recht behauptet, (Epimetrum zu Mommsens Ausgabe) in Syrien. In diesem Falle können wir mit großer Wahrscheinlichkeit mit Nöldeke eine griechische Urschrift der Continuatio annehmen.

Der Zweck der folgenden Zeilen ist, das Verhältnis der beiden Chroniken näher zu betrachten, wozu noch der Umstand berechtigt, daB diese Beziehungen noch nirgends ausdrücklich festgestellt sind, Brooks sogar die Continuatio offenbar gar nicht gekannt hat.

1.

Die byzantinischen Kaiserdaten der beiden Chroniken bieten nichts Bemerkenswertes. Sie sind der Anlage beider Werke entsprechend verschieden behandelt, da der Syrer Brooks' (SB) in Annalenform berichtet, der Continuator (Con.) aber die Ereignisse der byzantinischen Geschichte nur als chronologisches Gerippe für den Aufbau seiner Ge-

1) L. Schw., Kritische Betrachtung der lateinisch geschriebenen Quellen zur Eroberung Spaniens durch die Araber. Göttinger Dissertation, Celle 1894. 
schichte des Islam benützt. Der erste bemerkenswerte Unterschied findet sich in der Behandlung Muavijjas II. Bei Con. wird dieser Kalif lobend erwähnt, dagegen von SB ganz ausgelassen. Dies findet seine Erklärung darin, daB Muavijja wohl in Syrien (Damaskus) anerkannt wurde, nicht aber in Mesopotamien. Über die Erwähnung bezw. Nichterwähnung Muavijjas in anderen Werken vergleiche man übrigens die Ausführungen Nöldekes. ${ }^{1}$ )

Die Verfasser beider Chroniken wissen von einer Ermordung Marwâns nichts $\mathrm{zu}$ berichten. Von dem böswilligen Klatsch, den die Anhänger der Sufjaniden den Marwaniden anzuhängen sich bemühten ${ }^{2}$ ), und den Wellhausen in seiner Geschichte der Umajjiden mitteilt ${ }^{3}$ ), scheinen sie also nichts $\mathrm{zu}$ wissen oder wenigstens nichts wissen $\mathrm{zu}$ wollen, stehen demnach hier auf Marwanidischem Standpunkt.

Valid und Umar II finden sich in beiden Chroniken übereinstimmend charakterisiert. Dies ist Brooks, der Con. nicht kannte, natürlich entgangen, so daB er erklärt, zur Charakteristik Valids kein entsprechendes Gegenstück zu finden, bei Umar nur das ganz entgegengesetzte Urteil des Theophanes als merkwürdig anführt. Auffallend ist dabei, daB hier das Urteil des streng kirchlichen Theophanes dem des ebenso strenggläubigen Mönches von Carrhae und dem des religiös ziemlich indifferenten (nach Nöldeke monophysitischen) Verfassers der Continuatio gerade entgegengesetzt lautet. Der Grund für diese Erscheinung mag darin zun suchen sein, daB Theophanes in Umar lediglich den Feind byzantinischen Kaiser- und Kirchentums, die beiden anderen aber ihren zwar strengen, aber auch gerechten und besonders rechtmäBigen Herrscher sahen. ${ }^{3}$ )

Wenn Con. die Eroberung Spaniens berichtet, SB dagegen nicht, so liegt dies wohl daran, daB der Verfasser von Con. dem Regierungszentrum viel näher stand und auch alle Waffentaten des Umajjidenhauses mit gröBter Teilnahme verfolgte, während SB nur solche Ereignisse berücksichtigt, die zu seiner engeren Heimat Mesopotamien und zum byzantinischen Kaiserreich in näheren Beziehungen standen. So erklärt sich auch, daB er den Bulgarenkrieg vom Jahre 717 berichtet, Con. dagegen nicht.

2.

Quellen vermag Brooks für seinen Anonymus mit Namen nicht anzugeben, doch glaubt er, daB es dieselben seien, die auch Theophanes, Nikephoros, Michael Syrus, Pseudodionysius und Gregorius Abulfarag

1) Zur Geschichte der Omajjaden, ZDMG 1901 S. 683.

2) Nöldeke a. a. O. ZDMG 1901.

3) W., Das arabische Reich und sein Sturz. Berlin, Reimer 1902. 
für ihre Werke benützt hätten. Wenn nun Theophanes und Nikephoros ihre Araberberichte aus Con. geschöpft haben, was Mommsen in den Vorbemerkungen zu seiner Ausgabe behauptet, aber nicht beweist, so läge es nahe, Con. als gemeinsame Quelle für SB und die genannten Schriftsteller anzunehmen; doch ist nach den vorhergehenden Ausführungen der Gedanke an eine Benützung der Con. durch SB völlig ausgeschlossen.

Jedenfalls brauchen wir für hestimmte Teile der beiden Chroniken überhaupt keine Quellenbenützung vorauszusetzen, sondern können annehmen, daß die erzählten Ereignisse den Verfassern als selbsterlebt bekannt sind. Für diesen Fall müssen wir bestimmte Zeitpunkte als Grenze annehmen: was vor diese Zeitgrenze fällt, ist auf Grund von Quellen mitgeteilt, die späteren Ereignisse sind von den Verfassern selbst miterlebt. Nehmen wir an, daB die Verfasser etwa einen Zeitraum von fünfzig Jahren auf Grund eigener Erfahrung behandeln, so kämen wir bei SB etwa auf das Jahr 730 als Zeitgrenze. Die Zeit vor 730 müBte also auf Grund ron Quellenbenützung behandelt sein. Im Texte selbst finden wir keine Anhaltspunkte, die auf einen derartigen Systemwechsel hindeuteten; das Werk ist in seinen früheren Teilen, was es auch in den späteren bleibt: eine annalistische Aufzeichnung geschichtlicher Ereignisse aus dem Bereich der damaligen byzantinisch-orientalischen Kulturwelt, und zwar nach wie vor mit streng lokaler Färbung. Wir werden also wohl nicht viel fehlen, wenn wir auch in den Teilen vor 730 annalistische Carrhenser Aufzeichnungen sehen, die der Verfasser der Chronik wohl ausschlieBlich benützt - oder bis zum SchluB seiner Redaktionstätigkeit 784 lediglich fortgesetzt hat.

Dasselbe Verfahren läBt sich auch auf Con. anwenden. Die Chronik ist otwa 740 ontstandon, domnach fiele die Zeitgrenze um 690. Diese Zeitgrenze ist nun gar nicht so willkürlich gezogen, als es zunächst wohl erscheinen möchte: 683 vollzieht sich der Dynastiewechsel innerhalb des Umajjidenhauses, durch den das Kalifat von den Sufjaniden auf die Marwaniden übergeht. Damit wäre auch die auf den ersten Blick sonderbare Haltung des Verfassers gegenüber Muavijja und Marwân erklärt, indem wir annehmen, daB er für den ersten Teil seines Werkes Aufzeichnungen sufjanidischer Tendenz benützt, die weiteren Ereignisse auf Grund eigener Anschauung mitgeteilt, das Ganze aber zu einem in sich abgeschlossenen Werk verarbeitet hat mit der bestimmten Absicht, ein Bild zu geben von der allmählichen Ausbreitung des Islam und des islamitischen Reiches.

$M$ ïnster.

Herm. Brk. 